\title{
Mixing Qualitative and Quantitative Methods of Analyzing Poverty Dynamics
}

\author{
Christopher B. Barrett \\ Cornell University
}

March 2004

This work reflects many important lessons I have learned from collaborators on various projects in rural Ethiopia, Kenya and Madagascar. In particular, I thank Abdillahi Aboud, Larry Blume, Paul Box, Layne Coppock, Getachew Gebru, Johannes Lehmann, Peter Little, Winnie Luseno, Hussein Mahmoud, Nelson Mango, David Mbugua, John McPeak, Bart Minten, Festus Murithi, Hezron Nyangito, James Nyoro, Willis OluochKosura, John Omiti, Alice Pell, Max Pfeffer, Frank Place, Jean Claude Randrianarisoa, Jhon Rasambainarivo, Susan Riha and Kevin Smith for all they have taught me. These research collaborations have been made possible by generous funding from the Pastoral Risk Management Project of the Global Livestock Collaborative Research Support Program, funded by the Office of Agriculture and Food Security, Global Bureau, United States Agency for International Development, under grants DAN-1328-G-00-0046-00 and PCE-G-98-00036-00, the Rural Markets, Natural Capital and Dynamic Poverty Traps in East Africa project, funded through USAID grant LAG-A-00-96-90016-00 to the BASIS CRSP, USAID's Strategies and Analyses for Growth and Access (SAGA) cooperative agreement, number HFM-A-00-01-00132-00, and a Coupled Natural and Human Systems grant from the Biocomplexity program of the National Science Foundation. The views expressed here and any remaining errors are mine alone and do not represent any collaborator, past or present, nor any official agency.

(c) Copyright 2004 by Christopher B. Barrett. All rights reserved. Readers may make verbatim copies of this document for non-commercial purposes by any means, provided that this copyright notice appears on all such copies. 


\section{Mixing Qualitative and Quantitative Methods of Analyzing Poverty Dynamics}

Persistent poverty has plagued rural Africa for generations and, by some accounts, is becoming more widespread and entrenched. As a consequence, governments and donors have renewed and intensified their commitment to poverty reduction. This is reflected around the continent in poverty reduction strategy papers (PRSPs), efforts at decentralizing public goods and services delivery and the rise of participatory poverty appraisals intended to empower the poor, and a range of other policy changes. In some cases, one can legitimately wonder about the extent to which these reforms are heartfelt, rather than merely rhetorical and political, and the extent to which national and international elites are prepared to make sacrifices so as to advance an authentic poverty reduction agenda. But as one who has worked on problems of African poverty for two decades now, I feel quite comfortable asserting that there has been a palpable increase in recent years in the attention paid and sincerity surrounding questions of poverty reduction on the part of policymakers and donors.

Increased attention paid to the blight poverty leaves on society places an onus on researchers to generate relevant, accurate and timely analysis of the nature and causes of persistent poverty. Policymakers and donors need to know who are the poor, how large are their numbers, how deep is their poverty, and where they can be found. These questions have been probed in depth for decades, typically using cross-sectional methods of data collection and analysis. What is new and exciting is the question of poverty dynamics: who among the poor will naturally pull themselves up by their bootstraps and exit poverty and who will stay poor for a long period - a lifetime or more - unless communities, governments and donors take appropriate interventions?

There seems a fundamental difference between short-term deprivation - transitory poverty - where the poor have every expectation of becoming non-poor reasonably soon, and long-term deprivation, the chronic or persistent poverty that too often brings hopelessness. While any sort of poverty is plainly undesirable, persistent poverty strikes 
most of us as especially odious. Widespread concern nonetheless falls short of offering a clear and sensible strategy for combating persistent poverty. This requires careful study of the etiology of persistent poverty - its correlates and causes - and rigorous evaluation of alternative means of helping people avoid or escape persistent poverty. This demands rethinking of the methods we social scientists deploy in studying poverty.

To be sure, there have been notable advances in recent years in the toolkit analysts employ in studying poverty. Economists have made important advances in studying African poverty over the past decade, due in no small part to broad-scale use of the rigorous Foster-Greer-Thorbecke (1984) class of poverty measures, the increasing availability of nationally representative survey data, even panel data offering multiple longitudinal observations on individuals and households, and important efforts at disseminating cutting edge analytical methods through the African Economic Research Consortium (AERC) and several leading universities around the continent, including the University of Nairobi. At the same time, social scientists coming from anthropological and sociological traditions have likewise pushed the frontiers of our understanding of poverty forward, especially through the development, refinement and dissemination of various participatory methods and careful ethnographic and social analysis. The need for rethinking of methods arises not due to any failure on the part of researchers analyzing poverty to develop their disciplinary toolkits.

Rather, the need for some rethinking of methods arises from the complex, multidimensional nature of the concept of poverty itself. Poverty reflects at once (i) resource insufficiency, commonly manifest in low incomes and expenditures, (ii) vulnerability to adverse shocks such as illness, violence, and loss of livelihood, and (iii) powerlessness in the political, social and economic life of one's community and country (World Bank 2001). No single measure, no matter how cleverly designed nor carefully measured, could ever provide an encompassing treatment of so complex a concept.

As a result, all the different measures and methods we presently use are flawed, even when practiced skillfully. Consider, for example, some of the flaws of the metrics we 
economists commonly use. Household expenditures increase with purchases of alcohol, firearms and tobacco and with the need to pay for medical treatment for ill or injured family members or for reconstruction of homes damaged in civil unrest or natural disasters. Since we commonly interpret higher expenditures to reflect a higher level of well-being, expenditures are vulnerable to increased payments for "bads" rather than “goods”. Similarly, income measures of well-being can rise as people substitute work for leisure in response to increased stress, a phenomenon I previously termed "immiserized growth” (Barrett 1998). Yet because longer hours worked translate into higher income, our conventional inference that higher incomes means superior welfare runs afoul of reality. One could similarly critique qualitative methods used by non-economists. And there has indeed been much inter-disciplinary sniping over the years about the shortcomings of different methods.

But just because the practitioners of different methods of poverty analysis have commonly been in conflict, does this mean that the methods are necessarily in conflict? The fundamental claim of this paper is that all of our extant (and prospective) social scientific methods are more narrow than the complex concept of poverty they try to elucidate, too narrow indeed to be fully up to the important task of providing a full and accurate characterization of the nature and etiology of persistent poverty .

Thus there exists some inherent complementarity between qualitative and quantitative methods. The situation is rather like the parable of the blind men and the elephant. One, holding the trunk believed the beast to be a mammoth python, while another, touching an enormous leg, thought it a tree, and a third, feeling the thick hide of the animal's torso, was sure he had hold of a rhinoceros. Each had discovered an important but incomplete truth. Without sharing their findings, they could never divine the majesty of the complex beast, the elephant. So too must we can learn how to integrate methods in field-based research - what Kanbur (2003) terms "simultaneous mixing” - or to iterate between methods - "sequential mixing" - so as to significantly improve the quality of our analyses of poverty, perhaps especially poverty dynamics. 
This paper outlines my current thinking and recent experience in mixing qualitative and quantitative methods of data collection and analysis so as to gain a firmer and more useful understanding of poverty dynamics, especially in rural Kenya. The next section explores the very real differences between qualitative and quantitive poverty analysis methods. These differences make them useful complements. Then I briefly discuss key lessons I have learned from four multi-year research projects in Kenya in which I have tried to implement mixed qualitative and quantitative research methods with a range of colleagues from animal science, anthropology, economics, geography, range science, sociology and soil science.

\section{Real and False Differences}

Qualitative and quantitative methods differ in important ways. But one must be careful to identify precisely the dimensions of those differences. My contention is that the differences between qualitative and quantitative methods are commonly misunderstood and that this misunderstanding impedes fruitful mixing of methods.

So what are the important dimensions of difference between the methods? Kanbur (2003) goes into this issue in far greater detail than I have space for here. But let me emphasize four key differences between qualitative and quantitative methods.

The first is with respect to data collection methods. The breadth versus depth dichotomy advanced by Carvalho and White (1998??) - or even a unidimensional continuum ranging between these two end points - appears unhelpful, incorrect, or both. In my experience, it seems that a more apt representation might be Euclidean, ranging from specific to general coverage on one axis and from passive to active population involvement in the research on the other axis, as depicted in Figure 1. Qualitative autobiography would occupy one corner (specific/active) of that box, a quantitative census the opposite corner (general/passive), with considerable opportunity for creative combination of qualitative and quantitative methods in between. Where one locates 
one's work within that grid ought to depend upon the objectives of the research, the nature of the subjects, and the human and financial resources available to do the job.

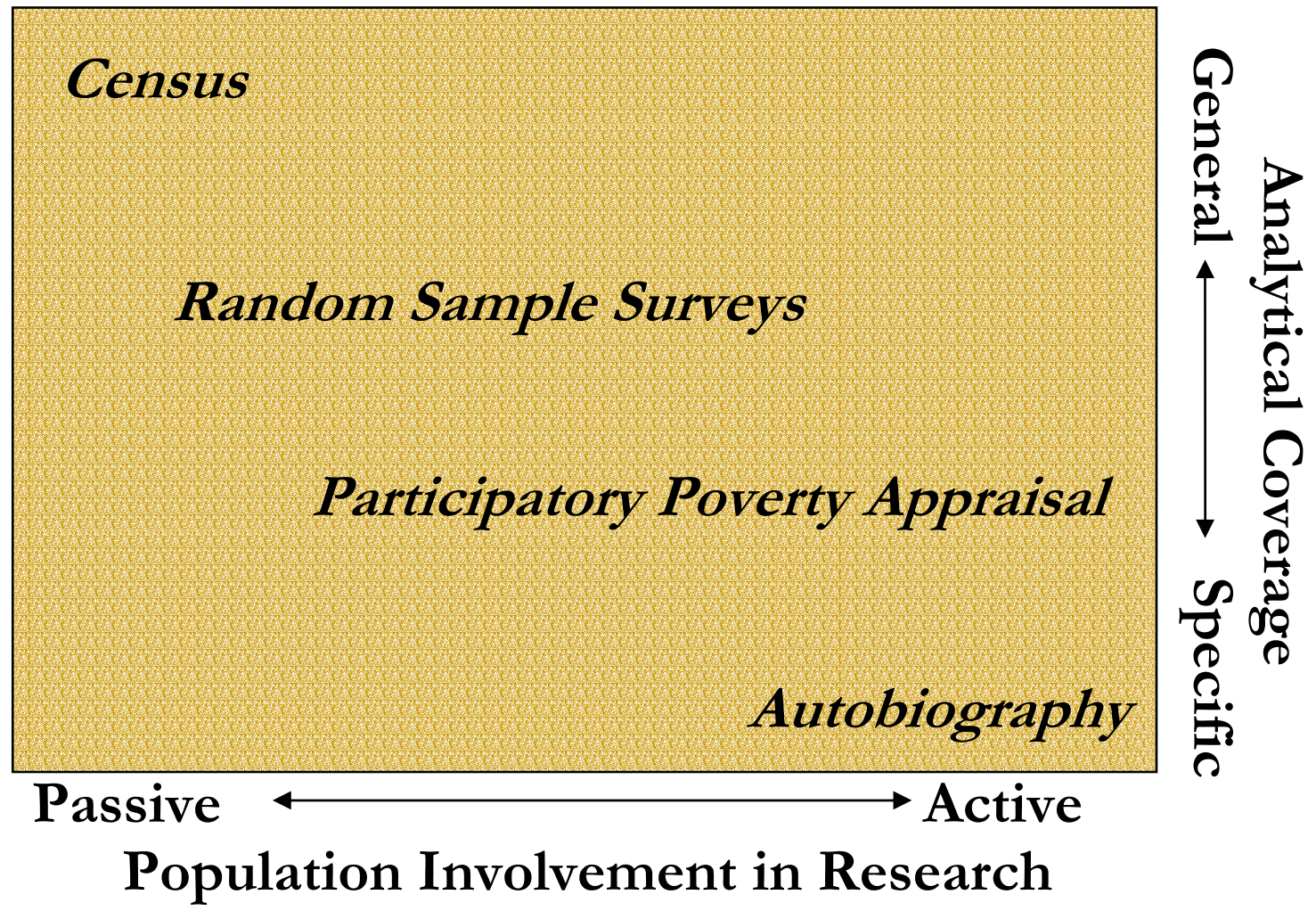

\section{Figure 1: Differences According To Data Collection Method}

The second dimension along which important differences arise concerns the type of data one collects. There exist three basic data types: (i) categorical data, including such data as identifying characteristics (e.g., gender, race, religion, clan, ethnicity), explanations and histories, can be distinguished from (ii) ordinal data - have things improved, stayed the same or gotten worse? what are your greatest fears? - for which a clear ordering exists among categories but there is no measurable "distance” between categories, and (iii) cardinal data (e.g., incomes in monetary units, children's weight or height measures) for which numeric ratios and intervals hold precise meaning. Note that the difference is

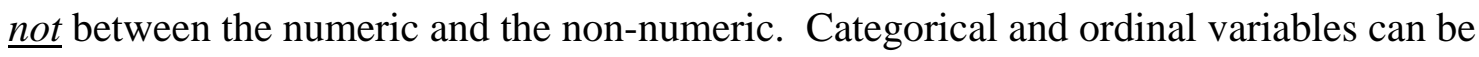
given numeric representation. Quantitatively-minded social scientists do this all the time using dummy variables. But those of us who like to use relatively more sophisticated econometric techniques in analysis tend to depend more heavily on cardinal data. 
The third dimension of important difference concerns the method of analysis one applies to data of whatever sort, collected by whichever means. The deductive tradition of economics differs markedly from the inductive tradition of anthropology. This difference is of course closely related to the specific-general data collection methods distinction drawn earlier, for one tends to collect data according to the analytical methods one plans to employ later. Where the general-to-specific, deductive approach most economists follows emphasizes the universally applicable signal in a given data set and has desire aggregability properties, the specific-to-general, inductive approach followed by most ethnographers and historians allows for fresh insights and honors the idiosyncratic elements of any given person or community’s experience.

Finally, and closely related to the preceding three differences, quantitative analysts commonly rely on deductive methods and general, random sampling in order to be able to speak to larger-scale decision-making units: national governments and international donors. Policy-oriented poverty economists like to try to capture "the big picture" and attempt to "speak truth to power”. Qualitatively-oriented researchers, meanwhile, are far more likely to be concerned about returning research findings directly to the population under study and to using the research experience to empower the poor directly, rather than trusting that policy changes on high might filter down to improve the lot of the poor within a reasonable period of time. The ultimate audience for research thus commonly differs somewhat between poverty researchers from the qualitative and quantitative traditions. Of course, this also helps account for the primacy of economic analysis in high-level policy debates about poverty and the striking under-representation of good qualitative analysis in those fora.

Having tried to define the meaningful differences between qualitative and quantitative methods of poverty analysis, it is important as well to debunk a few myths about differences that I do not believe to exist. Claims of ethical superiority - typically that qualitative methods are somehow less "extractive” than quantitative methods based on closed-ended survey instruments and complex statistical analysis - typically reflect 
highly selective association of particular research projects with general research methods. Research ethics are indisputably important and poverty analysts bear an obligation to do no harm to the population under study and, preferably, to serve as a truthful and energetic advocate for the poor. I do not believe there exists any robust correlation of researchers behavior with research methods, i.e., neither qualitative nor quantitative methods can defensibly claim ethical superiority over the other. There is much good and bad practice on both sides.

Nor is one approach necessarily more contextual than another. Quantitative researchers can probe extensively as to the history and genesis of current conditions. I already took issue with the mistaken perception that "qualitative” research is inherently nonnumerical. The best social analysis uses numbers to reflect inherently cardinal concepts, whether or not it uses statistical methods to make inferences about key hypotheses. Finally, and relatedly, math does not equal rigor. It is erroneous, yet I believe a common hubris of economists, that analyses based on careful statistical methods are somehow more "rigorous" than equally careful textual, historical or ethnographic analysis.

In short, bad practice is bad practice, whatever the method. There is no unconditional superiority of one class of methods, be they qualitative or quantitative, over another. Rather, the germane questions appear to be:

- " "when and how is good practice within a given class of methods still wanting?”

- “can another class of methods, well applied, fill in the blanks?” and

- " "how can one method validate the findings of another?"

The specifics of the answers to these questions depend very much on the precise question and site of one's research. But I have become convinced that in much poverty research, mixed methods approaches can work, each enhancing the efficacy of the other and reduces its weaknesses. To adapt and extend Leamer's (198??) famous injunction, it is sometimes important to take the "con" out of econometrics and to push beyond the "part" of participatory methods. Much of the challenge lies in reconciling vocabulary and data that do not correspond across different units or methods or analysis and in stimulating a culture of respectful inquiry that feeds on the creative tension of mixing methods. 
Lest I be misunderstood, let me be clear that I am not arguing that all poverty analysis needs to employ mixed methods. There are some classes of analysis that really lend themselves only to qualitative or quantitative analysis. For example, measurement of levels, change in and distribution of incomes or expenditures is a difficult and inherently quantitative task to which qualitative analysis contributes little directly, although parallel

qualitative analysis can enrich inference in causal, as distinct from descriptive, analysis of such data. So too with dietary intake and anthropometric data to establish nutritional status; these are inherently quantitative pursuits. It is equally true that "power” is a terribly elusive concept to operationalize quantitatively and thus studies of power relations and how individuals and communities organize politically to meet their basic needs and to advance their economic interests are best done qualitatively. Just because it is feasible to mix methods and desirable to do so in many circumstances doesn't mean that bread-and-butter disciplinary methods are outdated. Indeed, they are the bedrock of mixed methods of poverty analysis.

\section{Examples from Research in Rural Kenya}

For the remainder of this paper, I wish to share with you some of the lessons I have learned about mixing methods from four ongoing, multi-year collaborative research projects funded by the United States government, three by the United States Agency for International Development (USAID) and one by our National Science Foundation. The results from these projects remain preliminary at this point, so I do not focus on core research findings so much as on the process sequential or simultaneous mixing of qualitative and quantitative research methods.

\section{The PARIMA Project}

The Pastoral Risk Management (PARIMA) project, funded by the Global Livestock Collaborative Research Support Program (GL CRSP), operates in southern Ethiopia and northern Kenya. It is an interdisciplinary project with four lead investigators drawn from four separate academic fields (anthropology, economics, range science, sociology) and a 
variety of local and external collaborators across several disciplines. The project began in 1997 and is presently funded through 2006. PARIMA set out to improve understanding of the etiology of vulnerability among pastoralists in arid and semi-arid lands (ASAL) of east Africa and, derivatively, what sorts of policies, projects and technologies might best reduce that vulnerability. ASAL pastoralists are extraordinarily poor, with their poverty manifest in powerlessness (in national and often local politics), meager opportunities (the harsh climate limits agricultural options while poor infrastructure and low incomes limit non-farm ones) and tremendous vulnerability (to drought, flood, banditry, political violence, human and livestock disease, grain or livestock price shocks). PARIMA has concentrated on the latter two manifestations of pastoralist poverty, opportunities and vulnerability, and on interactions among these. In complex adaptive systems such as east African pastoralism, vulnerability can lead to sudden shifts in the opportunities faced by individuals, households or communities and, reciprocally, new opportunities can fundamentally reshape the risks these peoples face. Indeed, through multiple research methods our project has begun to uncover, if not yet fully explain, the stochastic poverty traps that appear to characterize these systems (Barrett and McPeak 2003, Barrett et al. in preparation, Lybbert et al. forthcoming, McPeak and Barrett 2001).

PARIMA has employed what Kanbur (2003) terms "simultaneous mixing” or "Bayesian integration”, wherein we follow an iterative approach, using one method to inform another, then back to the first, etc., keeping multiple methods interactive throughout the research process to update researchers' priors continuously. We have found that this built-in feedback loop yields a reasonably homeostatic (i.e., self-regulating) research mechanism that keeps pushing us towards our research objective and prevents us from drifting far from relevant or rigorous findings.

The feedback loop depends fundamentally on multi-faceted integration of qualitative and quantitative methods to ask and answer several generic questions:

1) What does it mean to be poor or vulnerable in this setting? How does this vary across individuals, households, and communities and over time? (i.e., are we asking the right questions of the right people at the right time?) 
2) Derivative from 1), are we measuring the correct variables and in the right manner? (i.e., which data collection method and what data type(s) best fit the question(s) at hand?)

3) Is our inference of the qualitative and quantitative data on those variables consistent (a) across research methods (a test of robustness) and (b) with local expressions of understanding of the problem(s) (a test of relevance).

Procedurally, this qualitative-quantitative integration has taken place roughly as follows.

Participatory appraisal and detailed direct field observation by team members preceded questionnaire design and survey site selection. This underscored issues the importance of which we had not previously appreciated. It helped us design a locally acceptable survey strategy (e.g., safeguarding project field staff against misperceptions of ethnic bias). “Ethnography” precedes "participatory” which in turn precedes "sampling” in the dictionary, and based on our experiences, I believe that sequencing generally ought to apply in the field, as well. Start by reviewing the relevant ethnographies of the area so as to be able to interpret well the products of participatory methods, then use the tools of survey-based data analysis to explore more precisely hypotheses that emerge from the PRA exercises.

We therefore began analysis on the basis of ethnographic and participatory rural appraisal (PRA) qualitative data to draw out patterns and explanations from a relatively small sample of non-representative respondents. This helped to clarify oft-misunderstood dynamics, for example with respect to the driving factors behind diversification out of pastoralism (Little et al. 2001), the role of ethnometeorological practitioners in providing climate forecasts in pastoral communities, (Luseno et al. 2003), or the absence of classical tragedy of the commons effects in southern Ethiopian rangelands (Lybbert et al. forthcoming), and to identify issues we had not sufficiently emphasized before (e.g., human health (Smith et al. 2000). We then presented these findings, our assessments of the extant literatures, and a draft Phase II, survey-led research design to a workshop of largely external stakeholders (donors, local and national governments, NGOs, and local researchers) for their feedback and some on-the-spot revision and re-presentation by our 
team, with further feedback. For the past four years we have therefore been following up the initial qualitative work with collection and preliminary analysis of quantitative data generated by repeated quarterly surveys among almost 750 individuals in 330 households across 11 sites in southern Ethiopia and northern Kenya. We have used this method effectively to explore whether pastoralists use and might benefit from modern climate forecasting techniques (Luseno et al. 2003, Lybbert et al. 2003), what constrains poor pastoralists from making better use of livestock marketing channels (Barrett et al. 2003, Barrett and Luseno forthcoming, Osterloh et al. 2004)

This is not, however, a strictly sequenced process, but a simultaneous process of ongoing dialogue between the qualitative and quantitative components of the project. We follow up quantitative survey analysis with qualitative exploration of anomalous results and puzzles and, reciprocally, follow up interesting qualitative findings with structured survey modules. For example, by asking individuals to report how many animals they owned and then adding up across individuals within households, we inadvertently discovered systematic overlapping claims to animals, revealing the importance of complex property rights in animals defined by the social origins of the livestock. This is both a potential (partial) explanation of the pastoralist marketing puzzle - why pastoralists' sales of livestock are typically weakly responsive to changing market or ecological conditions and a natural adaptation to the market problem, wherein breeding stock are largely unavailable for purchase, so communities tie others' hands to prevent the export of fertile heifers. Similarly, our questionnaires integrate open-ended questions that are designed to explore matters tough to frame precisely through traditional survey instruments (e.g., historical perceptions, indigenous climate forecasting methods). And we simultaneously pursue studies of livestock marketing through quantitative analysis of price data and household and market-level surveys of transactions data and through intensive participant observation and interviewing of traders so as to understand the social relationships that underpin trader networks. I have found that this ongoing, creative tension between qualitative and quantitative methods helps illuminate both key findings that hold up across disciplinary research traditions and findings that, while interesting, appear fragile and therefore a risky foundation for policy prescription. 
Moreover, the research is intended to be integrated with project's outreach activities which include community-level participatory identification of priority needs so as to help spark pilot activities to be accompanied by qualitative action research. We try to follow the traditions of bidirectional research-extension linkages, wherein findings flow both from practitioners to researchers and vice versa. We use quantitative evidence derived from past survey rounds to inform focus group and community discussions, returning research findings directly to studied communities. It helps to have the subject groups themselves engaged in attempting reconciliation and explanation of data from different sources and methods. Reconciling individual and group level responses is not always simple. Individuals may either deceive or speak more frankly in private, so one can never really be sure whether privately or publicly collected data offer more reliable representations of elusive truths. Hence the value of mixing methods and the fora from whence we derive data and thus analyses.

Let me offer a specific example of a mixed qualitative-quantitative tool that has proved quite useful (Smith et al. 2000, 2001). Our team developed an open-ended technique for getting people to identify and rank threats that concern them. We did this first in purposively/opportunistically selected focus groups, wherein the field leader (an anthropologist) took notes on explanations of these assessments and on the context. We recorded these ordinal data in numeric form, then subsequently constructed a simple (pseudo-cardinal) index. Having georeferenced all the points using a handheld global positioning system (GPS) unit, the geographer on our team could construct contour maps of risk assessment, polygonal maps of ethnic territories, and link these to extant biophysical data (e.g., rainfall), permitting quite useful and original spatial analysis. For example, we found that perceived vulnerability to drought is positively correlated with mean rainfall because of the differential mobility associated with various chosen activities. This led to a more fundamental, if not entirely original, insight that vulnerability to specific forms of risk is endogenous even when the biophysical shock itself (e.g., low rainfall) is exogenous. We could then also analyze the data using limited dependent variable econometric methods, using the ethnographic notes from the original 
focus group interviews to provide causal explanations of the observed statistical correlations. This process uncovered important structural patterns of heterogeneous risk assessment between men and women, rich and poor, Ethiopia and Kenya, pastoralists near and far from towns, etc. Since rangelands policies have historically treated pastoralists as a homogeneous population, this analysis has revealed unintended distributional and targeting effects of past policies (e.g., borehole development, pasture improvement). Of course, the lingering questions from the first round of work concerned the representativeness of risk assessments by purposively selected groups and the intertemporal stability of risk assessments. We therefore built the participatory risk assessment instrument into individual-level questionnaires fielded every three months over the course of two years so as to track more micro-level and temporal variation in risk assessment and to match randomly sampled individuals' ex ante risk assessment to their ex post experiences of shocks. We are now analyzing those data and should have results to share within a few months.

\section{The BASIS CRSP Project}

The Rural Markets, Natural Capital and Dynamic Poverty Traps in East Africa project, funded by USAID’s BASIS CRSP from 2000-2004, is likewise an interdisciplinary project with a variety of local and external collaborators (e.g., ICRAF, KARI, University of Nairobi in Kenya) across several disciplines covering two sites in the central and southern highlands of Madagascar, three sites in the central and western highlands of Kenya, as well as the northern Kenyan rangeland sites also covered by PARIMA. Through empirical analysis using mixed qualitative and quantitative methods of data collection and analysis, the BASIS project aims to identify best-bet strategies to help poor smallholders escape the interrelated problems of chronic poverty and on-farm natural resource depletion . We are trying to determine the incidence, severity and causal linkages behind prospective "poverty traps", as well as to identify the most promising approaches to reducing the incidence and severity of chronic poverty, especially in ways that support agricultural productivity growth and repletion of degraded soils. 
Studying poverty dynamics is even more complicated than measuring welfare at a single point in time, no matter which method(s) one employs. Repeated observations on the same respondents creates longitudinal observations on a cross-section, in the case of the BASIS project, of households. Intertemporal comparisons of real (i.e., inflation-adjusted) measures of income or expenditures depend fundamentally on the deflators used. Problems of sample attrition, household splitting or consolidation - especially if these phenomena prove non-random ${ }^{1}$ - changing survey designs and survey implementation teams, etc. can all affect inference by subtly changing the statistical representativeness of the panel sample, the definition of variables, or both. Furthermore, life cycle effects may come into play if households tend to, for example, accumulate assets through their adult working years and then decumulate assets later in life, although the limited direct evidence on the importance of these effects suggests they may be limited in developing country settings. ${ }^{2}$ We suspect that life cycle effects may be further attenuated in rural Africa by the advent of the HIV/AIDS pandemic, which commonly necessitates rapid liquidation of assets to meet health care costs.

Furthermore, the causal mechanism underpinning observed welfare dynamics - and, derivatively, what policy might do to prevent descents into poverty and to facilitate climbs out of it - do not automatically appear even when we measure income, expenditure or asset transitions accurately. For example, while we know that just over ten percent of our Vihiga District sample fell into poverty between 1989 and 2002, while just over twenty percent climbed out of poverty over the same period, our quantitative survey data don't give us a clear indication as to why these transitions occurred for the particular households we see crossing the poverty line over time.

In order to breathe life into these numbers, to cross-check their accuracy and to gain deeper insights into the causality behind observed welfare transitions, we followed up the panel survey data collection with qualitative poverty appraisals in each site. This

\footnotetext{
${ }^{1}$ See Alderman et al. (2001), Falaris (2003) and Rosenzweig (2003) for good discussions of the problems of sample attrition and endogenously changing household structure, as well as some suggestive empirical evidence that concerns about attrition bias may be overblown in panel data sets from developing countries.
} 
involved both community-level focus group meetings and key informant interviews to try to establish local conceptualizations of poverty and community-level phenomena that have affected the observed trajectories of most households (Mango et al. 2004).

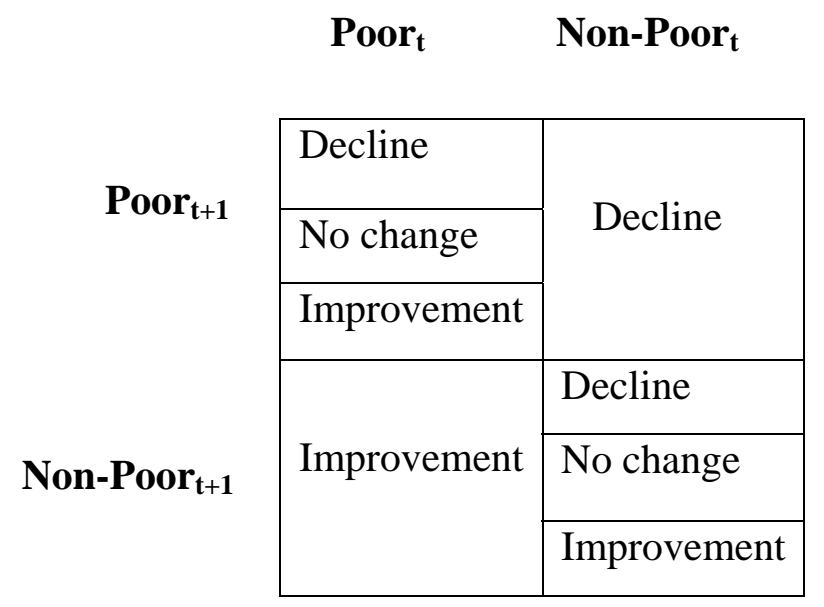

\section{Figure 2: Qualitative Sampling Design Based On Income Transition Matrix:} Stratification Based on Poor/Non-Poor Status and Intertemporal Welfare Change

We followed up these group meetings with in depth case studies of selected households so as to construct social-historical profiles of distinct household types characterized by observed welfare transitions. We constructed household-level real per capita income transition matrices - reflections of income status above or below the poverty line in each survey period - for each site in order to establish which households had been poor in each survey period, which had exited poverty from one round to the next, which had fallen into poverty and which had consistently stayed non-poor. We wanted to be sure to interview households representing each quadrant of this matrix defined by current and past position relative to an income poverty line. We then further broke down the subsamples who remained poor in both periods and those who were nonpoor in both

\footnotetext{
${ }^{2}$ Deaton (1992, 1997).
} 
periods according to the direction of change in their income between periods: those with significant per capita income losses between periods, no significant change, and those who enjoyed significant per capita income gains from one survey round to the next (Figure 2).

Since our interest lies in welfare dynamics, and because some dynamics do not involve crossing the poverty line, we needed this further decomposition in order to capture the full range of measurable movements around, toward and away from the poverty line. In these household level interviews - and subsequent closing community meetings - we focused especially on understanding the historical context underpinning local households' strategies to improve their welfare and the pathways by which certain households collapse into or escape from poverty. By complementing our quantitative work with follow-up qualitative work ${ }^{3}$, we were able to get an independent check on our statistical findings, an improved understanding of what lay behind observed changes in household well-being over time, and a set of human interest stories that are somewhat easier to communicate to policymakers and interested laypeople than are econometric results (Barrett et al. in preparation).

The BASIS CRSP thus offers an example of sequential mixing of methods, where we use the intermediate outputs from quantitative, survey-based analysis as an input into qualitative work based on ethnographic interviewing techniques, participatory appraisal methods and historical analysis. The qualitative results are now being used to specify econometric models for more refined quantitative analysis of the survey panel data. This

\footnotetext{
3 The qualitative work was generously supported by Canada's International Development Research Centre (IDRC) and the Rockefeller Foundation, as well as the USAID BASIS CRSP.
} 
method of sequentially mixing offers considerable promise for shedding light both descriptively and analytically on poverty dynamics, not just in rural Africa but anywhere.

\section{The SAGA project}

The USAID Strategies and Analyses for Growth and Access (SAGA) cooperative agreement, which links U.S.-based researchers at Cornell and Clark Atlanta Universities with partner research institutions in Kenya, among other countries, takes a "bottom-up" perspective on the problem of persistent poverty and stagnant economic growth in subSaharan Africa, an approach that starts from the capabilities of individuals, households, and communities -- their productivities, their vulnerabilities, their institutions, and their environment -- and which considers in detail how economic and social development can and do play out at the ground level.. A bottom-up approach naturally invites complementary research from the social sciences other than economics. While we maintain a firm foundation in economics, anthropologists, geographers, political scientists, and sociologists are actively involved as full research partners. We also emphasize dynamic issues because although economic growth and poverty reduction are inherently dynamic concepts, the existing debate on policy reform and poverty has paid scant attention to the dynamics of income, wealth, and human development.

Understanding these dynamics will lead to a structural foundation for growth and development at a micro level.

In Kenya, the SAGA research program was developed through a consultative process among the participating institutions ${ }^{4}$ wherein we identified key policy-oriented research topics that could usefully feed into the PRSP and Kenya Rural Development Strategy (KRDS) processes. We settled on two core themes around which each participating institution's SAGA research is built: (i) reducing rural risk and vulnerability, and (ii) empowerment of the rural poor. These themes take aim squarely at the problem of chronic poverty as experienced by many rural Kenyans today. The research follows the

\footnotetext{
${ }^{4}$ The SAGA Kenya partners with Cornell and Clark Atlanta are the Institute for Policy Analysis and Research (IPAR), the Kenya Institute Of Public Policy Research and Analysis (KIPPRA), Egerton University’s Tegemeo Institute for Agricultural Policy Research, and the University of Nairobi’s Department of Agricultural Economics.
} 
simultaneous mixing design in that the institutions work in parallel on common topics following their own chosen methods, with regular interaction so as to facilitate feedback between, for example, those doing quantitative, survey-based work on the role of producer groups in improving small farmers' livelihoods and those doing qualitative case study research on how decentralization of agricultural extension services might (or might not) accomplish that same goal. We remain at a relatively early stage in the process, but there is considerable promise in learning to integrate methods and products across researchers and institutions in this manner.

\section{The NSF Biocomplexity Project}

In 2003, a group of biological and social scientists at Cornell, ICRAF and KARI began a five year research project aimed at uncovering the coupled dynamics of human and natural systems in farming communities in Kenya's central and western highlands with an eye toward getting a better sense of what interventions might help stem the interrelated problems of declining soil fertility and persistent poverty among smallholder farmers. Poverty dynamics in Kenya's rural highlands depend fundamentally on the interplay between agricultural productivity, the evolution of the soils, trees and waters on which crop and livestock productivity depend, and the status of rural financial, labor, land and product markets. This necessarily involves a great deal of interdisciplinary collaboration on technical questions surrounding the evolution of soil quality and farm productivity. But the NSF project, which links with and builds on the BASIS project, combines not only soil and animal scientists’ experimental data with economists’ observational data, almost entirely based on cardinal data collected using randomized designs and analyzed deductively, we also integrate open-ended discussions with farmers and focus groups intended to understand better smallholders' perceptions of the soils they work, how they perceive their farm management decisions to affect the future state of the natural resource base and their own farm's productivity, and the constraints they face in managing livestock, soils, trees and water as they think best. This “cognitive mapping” of the coupled dynamics of human and natural systems as perceived by and acted upon by smallholders has become an intrinsic component of and check on our efforts to map those dynamics using more traditional, quantitative methods. 


\section{The Way Forward: Walking On Two Legs}

An old proverb, the origins of which I cannot recall exactly, says "a man can stand on one leg, but he needs two to move forward”. This strikes me as an apt insight with respect to the analysis of poverty dynamics today. The social sciences have a range of proven methods available for use and one can reasonably stand by any one of them to replicate the sorts of descriptive analyses with which we have all become familiar. The challenge, however, is to move forward, to push beyond the descriptive to do truly analytical work as to the causality behind persistent poverty and, derivatively, what interventions at which scales, on what timing and by which actors are most likely to yield permanent improvement in the standards of living of Kenya's, or Africa's, poorest peoples. From my perspective, there is little choice but to work harder at integrating qualitative and quantitative techniques, through simultaneous or sequential mixing of methods. The best development scholars increasingly recognize the inherent complementarity of qualitative and quantitative methods in tackling so complex a concept and intractable a problem as persistent poverty.

Let me close with a few practical suggestions based on my limited experience in trying to mix methods in poverty research in rural Kenya. As Kenya launches its upcoming participatory poverty appraisal, it ought to situate this exercise within the sampling frame used for its upcoming nationally representative statistical survey. That way both efforts will be focusing strictly on the same population and inferences can be directly and fruitfully compared across methods. Similarly, upcoming survey rounds should include more open-ended and subjective questions about categorical and ordinal data, such as respondents' perceptions of risk and their sense of the causal mechanisms behind their current state of well (or not-so-well) being. Above all, it is essential to build multidisciplinary teams, to keep them operational for a period of several years, and to create and maintain incentives for regular feedback within the group and between the researchers and the communities under study. No one discipline or set of individuals has a monopoly on useful data, methods or theories relevant to the challenge of combating 
persistent poverty. But it takes some time to establish mutual trust, a common vocabulary, shared insights on the mechanisms at work in the populations being studied, common data storage and use protocols, etc. Experience tells me that such investments pay handsome dividends. But they tend to require leadership and some active effort at organizing to facilitate and encourage such multidisciplinary collaboration.

I have been fortunate to be a part of teams supported with multi-year research funding from the U.S. government for precisely such purposes. Such projects are distressingly rare, however. Governments and donors need to establish and fund multidisciplinary research apparatus capable of tackling the disparate dimensions of persistent poverty as manifest across nations as diverse as Kenya. This requires a change from the usual donor “hire a consultant” mindset. It also demands some real attention be paid to reconstituting graduate training in the social sciences in local universities, which have fallen into disrepair after years of underfunding, politicization and general neglect. These multidisciplinary teams need to draw increasingly from a skilled cadre of committed local researchers working independently and in concert with government and donors, perhaps backstopped by expert expatriate collaborators to help guide the effort and keep teams up-to-date with the most recent methodological advances in the disciplines.

The promise of mixed methods of social science research on poverty is considerable. This is not, however, an easy path to follow and will take some concerted effort on the part of researchers and the donors and governments that oversee and fund research. In Kenya and many other countries in which poverty is widespread and stubbornly persistent, the returns to simultaneous or sequential mixing of qualitative and quantitative methods of analysis strike me as quite high on average.

\section{References}

Barrett, Christopher B., "Immiserized Growth in Liberalized Agriculture," World Development, vol. 26, no. 5 (May 1998): pp. 743-753. 
Barrett, Christopher B., Francis Chabari, DeeVon Bailey, Peter D. Little and D. Layne Coppock, "Livestock Pricing in the Northern Kenyan Rangelands," Journal of African Economies, vol. 12, no. 2 (June 2003): pp. 127-155.

Barrett, Christopher B. and Winnie K. Luseno, "Decomposing Producer Price Risk: An Analysis of Livestock Markets in Northern Kenya” Food Policy, forthcoming.

Barrett, Christopher B., Paswel Phiri Marenya, John G. McPeak, Bart Minten, Festus M. Murithi, Willis Oluoch-Kosura, Frank Place, Jean Claude Randrianarisoa, Jhon Rasambainarivo and Justine Wangila, "Welfare Dynamics in Rural Kenya and Madagascar,” manuscript in preparation.

Barrett, Christopher B. and John G. McPeak, “Poverty Traps and Safety Nets,” December 2003 Cornell University working paper.

Deaton, Angus, "Household Saving in LDCs: Credit Markets, Insurance and Welfare,” Scandinavian Journal of Economics 94, 2 (1992): 253-273.

Deaton, Angus, The Analysis of Household Surveys: A Microeconometric Approach to Development Policy (Baltimore: John Hopkins University Press, 1997).

Falaris, E., "The Effect of Survey Attrition in Longitudinal Surveys: Evidence from Peru, Cote d'Ivoire, and Vietnam." Journal of Development Economics 70, 1 (2003): 133157.

Foster, James, Joel Greer and Erik Thorbecke, "A class of decomposable poverty measures,” Econometrica vol. 52, no. 3 (1984): pp. 761-766.

Kanbur, Ravi, editor, Q-Squared: Combining Qualitative and Quantitative Methods In Poverty Appraisal (Delhi: Permanent Black, 2003).

Little, Peter D., Kevin Smith, Barbara A. Cellarius, D. Layne Coppock and Christopher B. Barrett, “Avoiding Disaster: Diversification and Risk Management Among East African Herders,” Development and Change, vol. 32, no. 3 (June 2001): pp. 401-433

Luseno, Winnie K., John G. McPeak, Christopher B. Barrett, Getachew Gebru and Peter D. Little, "The Value of Climate Forecast Information for Pastoralists: Evidence from Southern Ethiopia and Northern Kenya,” World Development, vol. 31, no. 9 (September 2003): pp. 1477-1494.

Lybbert, Travis J., Christopher B. Barrett, Solomon Desta, and D. Layne Coppock, "Stochastic Wealth Dynamics and Risk Management Among A Poor Population," Economic Journal, forthcoming. 
Lybbert, Travis J., Christopher B. Barrett, John G. McPeak and Winnie K. Luseno, "Bayesian Herders: Updating of Rainfall Beliefs In Response to External Climate Forecasts,” October 2003 Cornell University working paper.

Mango, Nelson, Josephat Cheng’ole Mulindo, Gatarwa Kariuki and Wesley Ongadi, "Social Aspects of Dynamic Poverty Traps: Cases from Vihiga, Baringo and Marsabit Districts, Kenya,” January 2004 mimeo.

McPeak, John G. and Christopher B. Barrett, "Differential Risk Exposure and Stochastic Poverty Traps Among East African Pastoralists,” American Journal of Agricultural Economics, vol. 83, no. 3 (August 2001): pp. 674-679.

Osterloh, Sharon M., John G. McPeak, Hussein Mahmoud, Winnie K. Luseno, Peter D. Little, Getachew Gebru and Christopher B. Barrett, "Pastoralist Livestock Marketing Behavior in Northern Kenya and Southern Ethiopia: An Analysis of Constraints Limiting Off-Take Rates,” Report to the USAID Global Livestock Collaborative Research Support Program, December 2003.

Pell, Alice N., David M. Mbugua, Louis V. Verchot, Christopher B. Barrett, Lawrence E. Blume, Javier G. Gamara, James M. Kinyangi, C. Johannes Lehmann, Agnes O. Odenyo, Solomon O. Ngoze, Bernard N. Okumu, Max J. Pfeffer, Paswel P. Marenya, Susan J. Riha and Justine Wangila, "The Interplay Between Smallholder Farmers and Fragile Tropical Agroecosystems in the Kenyan Highlands,” February 2004 Cornell University working paper.

Smith, Kevin, Christopher B. Barrett, and Paul W. Box, "Participatory Risk Mapping for Targeting Research and Assistance: An Example Using East African Pastoralists,” World Development, vol. 28, no. 11 (November 2000): pp. 1945-1959.

Smith, Kevin, Christopher B. Barrett, and Paul W. Box, "Not Necessarily In The Same Boat: Heterogeneous Risk Assessment Among East African Pastoralists," Journal of Development Studies, vol. 37, no. 5 (June 2001): pp. 1-30. 